\title{
Treatment of brain metastases from lung cancer: challenging the historical nihilism concerning prognosis
}

The occurrence of brain metastases in lung cancer substantially affects the quality of life by the deterioration of neurocognitive functions of patients and has been considered an event that quite inevitably leads to death. The prognosis of such patients has been considered poor. Median overall survival of unselected patients with brain metastases from lung cancer managed with whole-brain radiotherapy (WBRT), which was a mainstay of management of these patients, was 3-4 months $(1,2)$. Historically, a standard treatment for brain metastases from lung cancer involved WBRT alone or WBRT combined with neurosurgical resection or stereotactic radiosurgery (SRS) for selected patients. The addition of SRS or neurosurgical resection to WBRT in patients with single brain metastasis prolonged overall survival (3-5). The use of chemotherapy for brain metastases from lung cancer has long been questioned because of the notion that drugs poorly penetrate through the blood-brain barrier, except for small-cell lung cancer (SCLC) due to its well-known chemoresponsiveness and a frequent presentation of brain metastases with extracranial progression. Despite the improvement of brain metastases control with WBRT, this treatment modality was not associated with improved overall survival in randomized clinical trials (6-9), and an increase in the risk of neurocognitive decline with WBRT use was demonstrated in some trials $(8,9)$. Currently, in WHO performance status $0-2$, patients with up to three brain metastases from non-small cell lung cancer (NSCLC), local therapy (surgery or SRS) without WBRT is recommended (10).

Additionally, it was demonstrated that the prognosis of patients with brain metastases is determined by variables other than therapeutic strategies. Initially, a good performance status, control of the primary tumor, no extracranial metastasis, and younger age were identified as factors associated with improved survival in recursive partitioning analysis (RPA) (1). It was observed that a subgroup of patients might have longer survival than predicted by RPA (11). To assist the selection of proper personalized therapy, several new prognostic indices have been developed, e.g., diagnosis-specific graded prognostic assessment (DS-GPA) (12) and, more recently, graded prognostic assessment for lung cancer using molecular markers (Lungmol GPA) indicating that biological factors should be strongly considered in the therapeutical decision-making (13).

A question one may ask is how to put these data on the management of brain metastases into the context of the constantly changing and evolving landscape of treatment of lung cancer. Targeted, personalized treatment is available for both NSCLC and SCLC. The detailed guidelines exist for molecular testing in NSCLC, before initiating first-line therapy (10). Novel therapies such as targeted agents for brain metastases in lung cancer with driver mutations and the immune checkpoint inhibitors were revealed to have greater intracranial efficacy compared with conventional chemotherapy $(14,15)$. Also, recently, in extensive-disease (ED) SCLC, we have witnessed an encouraging move of introducing immunotherapy to standard chemotherapy (16). Besides progress in biological therapies, immense technological progress in radiotherapy has been made with the introduction of image-guided radiotherapy (IGRT) and intensity-modulated radiotherapy (IMRT). Progress in radiological diagnostic with follow-up imaging with brain MRI may contribute to the early detection of brain metastases and, consecutively, increased adoption of SRS. This may promote research in the direction of the combination of these novel agents with SRS or WBRT in the case of multiple metastases. Molecular status may have an impact on the decision to delay brain radiotherapy in subgroups of patients, but there are insufficient data to make a more definitive recommendation. All these issues are discussed in this special issue on the radiotherapy of brain metastases from lung cancer.

Despite the growing use of SRS with the omission of WBRT, even in SCLC $(17,18)$, WBRT for brain metastases cannot always be omitted, and in such patients, concern arises about a neurocognitive decline, especially in the fragile, elderly population (19). In such cases, new radiation technologies, like IMRT, may be used for the preservation of memory, such as hippocampal avoidance (HA) (20). In a recent phase III trial, including 518 patients with multiple brain metastases referred for WBRT with random assignment to $30 \mathrm{~Gy}$ in 10 fractions to the whole brain + memantine + HA vs. the same approach without HA, it was demonstrated that WBRT with HA better preserves cognitive function after treatment compared with WBRT without HA, with no difference in intracranial control and overall survival (21). Thus, management of brain metastases from lung cancer requires a detailed and comprehensive discussion with patients on the trade-off between intracranial control and cognition, taking into account that the prognosis of such patients may not be as obscure as it was thought in the past due 
to progress in biological sciences and radiotherapy technologies. Again, this is a call for a multidisciplinary approach in the management of brain metastases in close cooperation with oncologists as well as neurosurgeons. In the exploratory analysis of the European Organization for the Research and Treatment of Cancer 22952-26001 trial, including 268 patients with brain metastases, patients undergoing SRS exhibited similar local tumor control to those undergoing surgical resection. The risk of early local recurrence was higher among patients undergoing surgery; however, the risk of late recurrence was higher among those undergoing SRS. Thus, a crucial issue would be to identify the patients who benefit from surgery alone with the omission of any form of radiotherapy (22).

All aforementioned considerations relate to the patients with preserved performance status who may benefit from the progress in the management of lung cancer. However, among patients with brain metastases from lung cancer, there is a significant proportion of patients with poor performance status, for whom WBRT has no benefit over the use of steroids alone (23). These patients should benefit from the early introduction of all measures of palliative care without radiotherapy, because such an approach improves the quality of life, especially in patients with lung cancer (24). A comprehensive review by Sharma and Mrugala (25) provides the evidence and recommendation for palliative care for patients with brain metastases during oncological treatment; more pertinent, however, are the palliative approaches to be adopted at the stage of the disease when there are no longer any viable surgical, radiation, or systemic options available, or if the patient's condition is too poor to continue any oncological treatment.

The Guest Editor and Contributors of this special issue of the Fournal of Thoracic Disease hope that clinicians will find the articles in this issue interesting and useful for their daily practice.

\section{Acknowledgments}

Funding: None.

\section{Footnote}

Provenance and Peer Review: This article was commissioned by the editorial office, Fournal of Thoracic Disease for the series "Radiotherapy for Brain Metastases from Lung Cancer". The article did not undergo external peer review.

Conflicts of Interest: The author has completed the ICMJE uniform disclosure form (available at http://dx.doi.org/10.21037/ jtd-2019-rbmlc-12). The series "Radiotherapy for Brain Metastases from Lung Cancer" was commissioned by the editorial office without any funding or sponsorship. LK served as the unpaid Guest Editor of the series. The author has no other conflicts of interest to declare.

Ethical Statement: The author is accountable for all aspects of the work in ensuring that questions related to the accuracy or integrity of any part of the work are appropriately investigated and resolved.

Open Access Statement: This is an Open Access article distributed in accordance with the Creative Commons AttributionNonCommercial-NoDerivs 4.0 International License (CC BY-NC-ND 4.0), which permits the non-commercial replication and distribution of the article with the strict proviso that no changes or edits are made and the original work is properly cited (including links to both the formal publication through the relevant DOI and the license). See: https://creativecommons.org/ licenses/by-nc-nd/4.0/.

\section{References}

1. Gaspar L, Scott C, Rotman M, et al. Recursive partitioning analysis (RPA) of prognostic factors in three Radiation Therapy Oncology Group (RTOG) brain metastases trials. Int J Radiat Oncol Biol Phys 1997;37:745-51.

2. Kepka L, Cieslak E, Bujko K, et al. Results of the whole-brain radiotherapy for patients with brain metastases from lung cancer: the RTOG RPA intra-classes analysis. Acta Oncol 2005;44:389-98. 
3. Patchell RA, Tibbs PA, Walsh JW, et al. A randomized trial of surgery in the treatment of single metastases to the brain. N Engl J Med 1990;322:494-500.

4. Noordijk EM, Vecht CJ, Haaxma-Reiche H, et al. The choice of treatment of single brain metastasis should be based on extracranial tumor activity and age. Int J Radiat Oncol Biol Phys 1994;29:711-7.

5. Andrews DW, Scott CB, Sperduto PW, et al. Whole brain radiation therapy with or without stereotactic radiosurgery boost for patients with one to three brain metastases: phase III results of the RTOG 9508 randomised trial. Lancet 2004;363:1665-72.

6. Aoyama H, Shirato H, Tago M, et al. Stereotactic radiosurgery plus whole-brain radiation therapy vs stereotactic radiosurgery alone for treatment of brain metastases: a randomized controlled trial. JAMA 2006;295:2483-91.

7. Kocher M, Soffietti R, Abacioglu U, et al. Adjuvant whole-brain radiotherapy versus observation after radiosurgery or surgical resection of one to three cerebral metastases: results of the EORTC 22952-26001 study. J Clin Oncol 2011;29:134-41.

8. Brown PD, Jaeckle K, Ballman KV, et al. Effect of radiosurgery alone vs radiosurgery with whole brain radiation therapy on cognitive function in patients with 1 to 3 brain metastases: a randomized clinical trial. JAMA 2016;316:401-9.

9. Brown PD, Ballman KV, Cerhan JH, et al. Postoperative stereotactic radiosurgery compared with whole brain radiotherapy for resected metastatic brain disease (NCCTG N107C/CEC.3): a multicentre, randomised, controlled, phase 3 trial. Lancet Oncol 2017;18:1049-60.

10. NCCN clinical practice guidelines in oncology (NCCN guidelines): non-small cell lung cancer. Ver. 6.2020. Published June 15, 2020.

11. Niemiec M, Głogowski M, Tyc-Szczepaniak D, et al. Characteristics of long-term survivors of brain metastases from lung cancer. Rep Pract Oncol Radiother 2011;16:49-53.

12. Sperduto PW, Kased N, Roberge D, et al. Summary report on the graded prognostic assessment: an accurate and facile diagnosis-specific tool to estimate survival for patients with brain metastases. J Clin Oncol 2012;30:419-25.

13. Sperduto PW, Yang TJ, Beal K, et al. Estimating survival in patients with lung cancer and brain metastases: an update of the graded prognostic assessment for lung cancer using molecular markers (Lung-molGPA). JAMA Oncol 2017;3:827-31.

14. Suwinski R. Combination of immunotherapy and radiotherapy in the treatment of brain metastases from non-small cell lung cancer. J Thorac Dis 2021;13:3315-22.

15. Bhandari S, Dunlap N, Kloecker G. Radiotherapy in brain metastases from EGFR-mutated non-small cell lung cancer. J Thorac Dis 2021;13:3230-4.

16. Horn L, Mansfield AS, Szczęsna A, et al. First-line atezolizumab plus chemotherapy in extensive-stage small-cell lung cancer. N Engl J Med 2018;379:2220-9.

17. Rusthoven CG, Camidge DR, Robin TP, et al. Radiosurgery for small-cell brain metastases: challenging the last bastion of preferential whole-brain radiotherapy delivery. J Clin Oncol 2020;38:3587-91.

18. Kepka L, Socha J, Sas-Korczynska B. Radiotherapy for brain metastases from small-cell lung cancer in distinct clinical indications and scenarios. J Thorac Dis 2021;13:3269-78.

19. Socha J, Rychter A, Kepka L. Management of brain metastases in elderly patients with lung cancer. J Thorac Dis 2021;13:295-307.

20. Abraham AG, Roa W. Hippocampal avoidance in prophylactic cranial irradiation for small cell lung cancer: benefits and pitfalls. J Thorac Dis 2021;13:3235-45.

21. Brown PD, Gondi V, Pugh S, et al. Hippocampal avoidance during whole-brain radiotherapy plus memantine for patients with brain metastases: phase III trial NRG oncology CC001. J Clin Oncol 2020;38:1019-29.

22. Churilla TM, Chowdhury IH, Handorf E, et al. Comparison of local control of brain metastases with stereotactic radiosurgery vs surgical resection: a secondary analysis of a randomized clinical trial. JAMA Oncol 2019;5:243-7.

23. Mulvenna P, Nankivell M, Barton R, et al. Dexamethasone and supportive care with or without whole brain radiotherapy in treating patients with non-small cell lung cancer with brain metastases unsuitable for resection or stereotactic radiotherapy (QUARTZ): results from a phase 3, non-inferiority, randomised trial. Lancet 2016;388:2004-14.

24. Temel JS, Greer JA, El-Jawahri A, et al. Effects of early integrated palliative care in patients with lung and GI cancer: a randomized clinical trial. J Clin Oncol 2017;35:834-41.

25. Sharma A, Mrugala MM. Supportive care for patients with brain metastases from lung cancer. J Thorac Dis 2021;13:3258-68. 


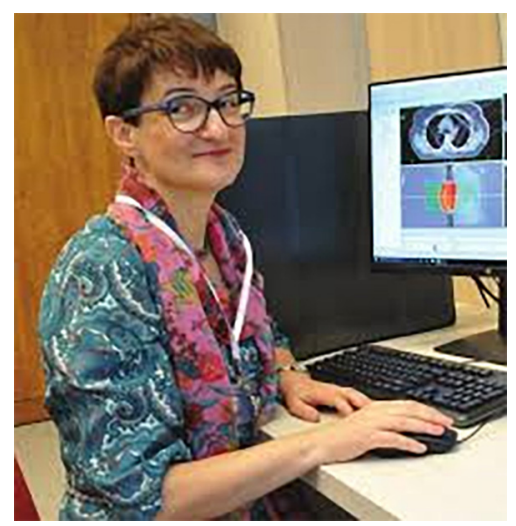

Lucyna Kepka

Lucyna Kepka

Department of Radiotherapy, Military Institute of Medicine, Warsaw, Poland. (Email: lkepka@wim.mil.pl) Submitted Sep 03, 2020. Accepted for publication Sep 28, 2020. doi: $10.21037 /$ jtd-2019-rbmlc-12

View this article at: http://dx.doi.org/10.21037/jtd-2019-rbmlc-12

Cite this article as: Kepka L. Treatment of brain metastases from lung cancer: challenging the historical nihilism concerning prognosis. J Thorac Dis 2021;13(5):3226-3229. doi: 10.21037/jtd2019-rbmlc-12 